\title{
Transformações contemporâneas no mundo do trabalho e consequências à aposentadoria
}

\author{
Contemporary transformations in the world of work and consequences of retirement
}

\author{
Christiane Pimentel e Silva*
}

\begin{abstract}
Resumo:
Uma das conquistas das reivindicações dos trabalhadores assalariados no início do século XX foi o surgimento da aposentadoria, criada, portanto, vinculada ao trabalho regulamentado. Contemporaneamente, a acentuada redução na contratação formal do trabalhador tem como uma de suas consequências a retração dos sistemas tradicionais de proteção ao trabalhador, aumentando o número de trabalhadores desprotegidos em detrimento da universalização dos direitos. Neste contexto de direitos sociais negados, destaca-se a aposentadoria, que na sociedade de trocas transformou-se em mercadoria, seguindo a lógica que já havia adentrado à área da saúde pública.
\end{abstract}

Palavras-chaves: Trabalho. Aposentadoria. Seguridade social.

\begin{abstract}
:
One of the achievements of the claims of employees in the early twentieth century was the emergence of retirement, set up, therefore, linked to regular work. Simultaneously, the sharp reduction in formal employment of the worker has as one of its consequences to a decline of traditional systems of protection to workers, increasing the number of unprotected workers at the expense of universal rights. In this context, social rights denied, stands out retirement, the company that trade has become a commodity, following the logic that was already inside the area of public health.
\end{abstract}

Keywords: Work. Retirement. Social security.

\section{Introdução}

Nas últimas cinco décadas, o mundo do trabalho sofreu profundas transformações em sua materialidade e subjetividade, provocando graves impactos na vida social como o aumento da concentração da renda, precarização e informalização ampliadas do mercado de trabalho. O enxugamento aparente da fábrica pela eliminação de trabalhadores com contratos regulares e a multiplicação das formas de

\footnotetext{
* Universidade Federal do Pará (UFPA). Bacharel em Serviço Social pela UFPA. Mestranda do Programa de Pós-Graduação em Serviço Social da UFPA. E-mail: lilacbrik@yahoo.com.br.
} 
trabalho parcial, precário ou terceirizado fizeram com que muitos teóricos advogassem o fim do trabalho, substituindo o valor-trabalho como a principal força produtiva pelo conhecimento científico.

Ao longo deste texto, procura-se demonstrar que as teses sobre o fim do trabalho e a substituição da força produtiva pelo conhecimento técnico desconsideram que: a) o trabalho é uma atividade humana essencial para a produção de bens socialmente úteis, e por isso vital à reprodução da vida material; b) somente o trabalho é capaz de gerar valor; e c) o sistema capitalista, desde o seu surgimento, utiliza de forma combinada o trabalho e a ciência (tecnologia).

Atualmente, o trabalho é mais complexificado e heterogêneo (ANTUNES, 2007), mas isso não nos permite afirmar que o trabalho não perdeu sua centralidade enquanto forma social. O que de fato aconteceu como consequência das inúmeras ocupações terceirizadas foi a perda da centralidade política dos trabalhadores, que por não se reconhecerem em sua unicidade histórica, não conseguem combater o ataque contra as conquistas trabalhistas, reduzindo cada vez mais a universalização de direitos sociais, como, por exemplo, a seguridade social, e, em especial, a aposentadoria.

A proteção social brasileira ${ }^{1}$ está sedimentada na "cidadania regulada", uma noção de cidadania subordinada ao vínculo profissional legalizado, que se reduz ao acesso de benefícios destinados aos contribuintes previdenciários. Assim, os direitos sociais são limitados a grupos corporativos, e não se universalizam, recriando desigualdades, transformando em "não cidadãos" os que não conseguem se enquadrar sob as regras do trabalho regularizado (SANTOS apud TELLES, 1999).

Sabe-se que a "cidadania regulada" não conseguiu envolver toda a sociedade civil, no entanto, por causa dos recentes processos de externalização e de terceirização da produção, a cada ano aumenta o número de trabalhadores que deixam de participar dela, conforme a tabela 1, vivenciando-se uma intensa degradação dos direitos sociais do trabalhador.

\footnotetext{
${ }^{1}$ Mota (2000) refere que a proteção social no Brasil remonta à formação do proletariado urbano, a partir dos anos 1920, com o surgimento da lei Eloy Chaves, que criou as caixas de aposentadorias e pensão para empregados das empresas ferroviárias.
} 
Tabela 1 - \% de emprego formal no total da ocupação

\begin{tabular}{ll}
\hline 1980 & 2000 \\
\hline 45,4 & 42,7 \\
\hline
\end{tabular}

Fonte: Elaboração própria a partir de Pesquisa Nacional por Amostra de Domicílio, IBGE.

Diante do quadro de persistência das elevadas taxa de desemprego e de desregulamentação trabalhista questiona-se sobre o futuro da aposentadoria, levando em consideração que a previdência social brasileira - de acordo com Art. 196 da Constituição de 1988 - é financiada pelo mercado de trabalho, uma vez que os vínculos trabalhistas formais supõem descontos em folha de pagamento e taxação sobre faturamento e lucro.

\section{Quando a centralidade do trabalho é negada}

a) O trabalho qualificado

Autores como Lazzarato e Negri (2001) afirmam que o trabalho taylorizado deixou de cumprir um papel estratégico na produção, substituído pelo que denominam de "trabalho imaterial", entendido como uma categoria de trabalho que não transforma diretamente a natureza, e sim produz e reproduz comunicação, sendo um processo subjetivado que compreende as atividades relacionadas à produção audiovisual, publicidade, moda, marketing ${ }^{2}$, telemática, informática, desenvolvimento de software etc.

Os autores também entendem que as novas configurações do mundo do trabalho, principalmente por sua dimensão subjetiva do trabalho imaterial, têm como consequência uma superação efetiva do sistema capitalista e uma emancipação humana do trabalho alienado. As reflexões que se seguem pretendem abordar tais afirmativas.

Em atividades altamente intelectualizadas como a microeletrônica, robótica ou o sistema de comunicação/informação, onde a aplicação exacerbada de tecnologia

\footnotetext{
${ }^{2}$ Segundo o dicionário Houaiss, marketing se refere à estratégia empresarial de otimização de lucros por meio da adequação da produção e oferta de suas mercadorias ou serviços às necessidades e preferências dos consumidores, para isso recorrendo a pesquisas de mercado, campanhas publicitárias, atendimentos pós-venda etc.
} 
reduziu ao máximo o trabalho vivo, ainda percebe-se a vigência do trabalho estranhado - pois tanto o maquinário tecnocientífico, quanto a informação representam trabalho humano acumulado no passado - que podem aumentar as formas de extração da maisvalia, mas nunca por meio da completa ausência do trabalho vivo.

A robótica e automação não se produzem sem o projeto, a confecção e a programação humana. Além disso, a flexibilidade e a superfluidade das inovações tecnológicas resultam que, de um modo geral, a maquinaria:

[...] perde valor de troca à medida que se podem reproduzir de modo mais barato máquinas de igual construção ou à medida que surjam máquinas melhores concorrendo com ela. Em ambos os casos, seu valor, por mais nova e vitalmente forte que ainda possa ser, já não é determinado pelo tempo de trabalho de fato objetivado nela mesma, mas pelo tempo de trabalho necessário a sua própria reprodução ou à representação da máquina mais aperfeiçoada [...]. Logo que se introduz maquinaria em qualquer ramo da produção, aparecem, passo a passo, novos métodos para reproduzi-la mais barato e aperfeiçoamentos que atingem não só partes ou dispositivos isolados, mas toda sua construção (MARX, 1996, p. 37-38).

Sendo assim, novas e constantes pesquisas de aperfeiçoamento e montagem são necessárias, mostrando que mesmo com o grande avanço tecnológico, a capacidade de trabalho humano não pode ser completamente dispensada. Na pesquisa ou mesmo na produção de uma nova máquina é preciso de trabalho humano um sistema produtivo informatizado não pode excluir o operador humano pois a máquina não é capaz de criar valor ou criar nova tecnologia, uma vez que não existe uma Inteligência Artificial $^{3}$ pura, nem sistema inteiramente automatizado a máquina é produto de trabalho anterior já objetivado.

No capítulo XIII de O capital, Marx (1996, p. 21) refere que a maquinaria é parte do capital constante e por isso não cria valor, somente "transfere seu próprio valor ao produto para cuja feitura ela serve", sendo inserida apenas parcialmente no processo de valorização, proporcionalmente ao seu "desgaste médio diário".

\footnotetext{
${ }^{3}$ Do inglês Artificial Intelligence (AI), refere-se ao desenvolvimento de sistemas de automação e robótica que por sua programação imitam o comportamento humano. Esse mimetismo aparente, no entanto, é apenas a execução correta de um programa e não gera, necessariamente, uma compreensão. Além disso, segundo Searle (1980), os sistemas artificiais de inteligência podem simular sintaxe (gramática), mas isso não significa que possuam semântica (sentido, consciência, compreensão).
} 
As tecnologias de informação e comunicação, conforme aponta Lessa (2003, p. 40), "só podem existir fora da subjetividade que as criou, revelando sua materialidade", de maneira similar à máquina, são realizadas pela capacidade humana de trabalho à medida que "não há nenhum ato de trabalho que não transforme o real", pois as "ideias possuem força objetiva", constituindo "forças materiais na determinação da história dos homens".

Se este trabalho é objetivado - ou dito de outro modo, torna-se externo ao homem para satisfazer (por suas propriedades intrínsecas) necessidades humanas sociais, sejam materiais ou espirituais - o trabalhador que produz as tecnologias que permitem a "revolução informacional" está vendendo sua força de trabalho para garantir sua reprodução. Deste modo, o "trabalho imaterial" também é apropriado por outrem, atendendo a regulamentações exteriores, determinadas unilateralmente pelos "demandes do trabalho", traduzindo-se uma "autonomia outorgada" (ROSENFIELD, 2004).

A hipótese de Lazzarato e Negri (2001, p. 14) não pode ser corroborada quando afirmam que "la época en que el control de todos los elementos de la producción dependía de la voluntad y de la capacidad del capitalista es superada: es el trabajo el que, cada vez más, define al capitalista, y no al contrario".

O trabalho sob a acumulação capitalista segue estranhado, mesmo em se tratando de um trabalho mais intelectualizado ou "imaterial", pois ao vender tecnologia ou informatização o trabalhador volta a ser um "despossuído", sendo obrigado a perpetuar o ciclo de reprodução do capital. Exposto, dessa forma, a lei do valor-trabalho não é abolida na contemporaneidade do ciclo de acumulação do capital, pois a sociedade produtora de mercadorias continua vivendo da valorização da extração de mais-valia.

O trabalho "imaterial" é mais intelectualizado quando comparado ao fordismo, mas não é de fato uma forma de emancipação/liberdade humana pelo trabalho, uma vez que seus processos são operacionalizados para instrumentalização e coordenação dos meios em função dos fins, ou seja, ainda trata-se de um trabalho produtor e

\footnotetext{
${ }^{4}$ Para Rosenfield (2004), a autonomia real remete à criação e à improvisação, enquanto que a autonomia outorgada significa o engajamento e a adesão aos objetivos da empresa pela obrigação de se engajar, isto é, um método concebido pelos agentes da concepção para o trabalhador.
} 
manipulador de conhecimento, abrigando em seu cerne dominação, repressão e exploração.

De acordo com Freitag (2004), esse saber objetivado, útil e instrumentalizado, despreza a dimensão histórica dos fenômenos, dos indivíduos e das sociedades, em função dos resultados práticos que possam ser extraídos, por essa "racionalidade instrumental", submissa e normatizada por resultados considerados aceitáveis apenas por ela. Ou, nas palavras de Adorno e Horkheimer (2006, p. 8-9, 22), o saber instrumental

[...] é poder, não conhece nenhuma barreira [...]. A técnica é a essência desse saber, que não visa conceitos e imagens, nem prazer do discernimento, mas método, a utilização do trabalho dos outros, o capital [...]. O processo técnico, no qual o sujeito se coisificou após sua eliminação de consciência [...] porque a própria razão se tornou um mero adminículo da aparelhagem econômica que a tudo engloba.

Ao capitalista, pouco importa se o trabalhador é chamado a opinar ou se permanece calado, desde que a produtividade do trabalho aumente, intensificada por meio de "formas de extração do sobre trabalho em tempo cada vez mais reduzido" (ANTUNES, 2006, p. 50). Sob a custódia do sistema produtor de mercadorias é necessário "aprender a aprender, [...] e, sobretudo, sabendo o que aprender, como aprender e como aplicar o conhecimento adquirido" (ROSENFIELD, 2004, p. 17). E por isso, o trabalho "imaterial" também pode ser realizado de forma flexível, atípico, sem qualquer garantia trabalhista, na forma de trabalho precário.

\section{b) O trabalho precarizado}

A produção em massa que garantiu a hegemonia norte-americana, dada pela produção nos moldes taylor-ford, mostrou-se ineficaz para o enfrentamento positivo da crise de $1973 .^{5}$ Assim foram adotadas as inovações tecnológicas e novas estratégias de gestão do trabalho e produção provenientes das grandes empresas japonesas. Essa

\footnotetext{
${ }^{5}$ Em 1973 com a crise do petróleo ocorreu a primeira grande recessão cíclica do período pós-guerras (19731975), fragilizando o setor financeiro mundial e alcançado os principais países capitalistas. Isto fez desencadear uma busca generalizada das empresas, por modelos de produção e gestão que permitissem minimizar custos e maximizar lucros no domínio político e econômico, formando doutrinas capazes de conter a ação do Estado frente às questões sociais (HARVEY, 1992).
} 
mudança de um modelo de produção atingiu diversas dimensões estruturais da economia à política, repercutindo diretamente na vida dos trabalhadores.

A nova proposta produtiva, o toyotismo, combina o uso intensivo de tecnologia de ponta, terceirização e flexibilidade para se ajustar a diferentes demandas, que, segundo Antunes (2006), de um lado reduzem de forma drástica o trabalho estável, de outro possibilitam um aumento do novo proletariado fabril e de serviços, por intermédio das formas de horizontalização, do acréscimo da lean production ${ }^{6}$ e da introdução da máquina informatizada, como a "telemática," que permite relações diretas entre empresas muito distantes.

A reestruturação produtiva implica o processo de desindustrialização que consiste em externalizar todas as funções da empresa que não valorizam diretamente o capital. Assim, são terceirizadas as funções de manutenção, contabilidade, recursos humanos, limpeza e, de acordo com Braga (2007), são externalizadas até mesmo as atividades de engenharia, projeto e controle financeiro, permanecendo na indústria "enxuta" apenas aquelas consideradas mais lucrativas.

Este contexto possibilitou o aumento da competição entre trabalhadores e, consequentemente, o enfraquecimento do poder sindical, que derivam do surgimento de um novo processo de contratação da mão de obra, impondo a flexibilidade nos acordos trabalhistas em detrimento de conquistas anteriormente alcançadas pelo trabalhador, como redução da jornada de trabalho, férias, décimo terceiro, seguridade social, dentre outras.

O surgimento do chamado "sindicalismo de envolvimento"7 está diretamente relacionado a essas mudanças estruturais e subjetivas da reestruturação produtiva, modificando principalmente a consciência sindical e a consciência política do trabalhador, nesse contexto histórico, impondo a incorporação do ideário da empresa, por meio de elevado grau de envolvimento com esta. Isto acontece porque o controle organizacional do sistema toyotista orienta permissões e proibições, tornando-as

\footnotetext{
${ }^{6}$ Tradução livre do inglês é produção enxuta. Na prática, este termo significa o "enxugamento" de grandes unidades produtivas mediante modalidades de flexibilização e desconcentração do espaço físico produtivo, que garantem o aumento da produtividade.

7 Para Alves (2001), o sucesso da instauração do toyotismo é articulada à neutralização do sindicalismo industrial de classe e sua transformação em um sindicalismo de empresa, corporativo e interlocutor exclusivo do capital. O sindicalismo de envolvimento passa a colaborar com a busca de soluções para os problemas da produção capitalista.
} 
internalizadas pelo trabalhador que deve encontrar seus limites, seu papel, seu espaço dentro da organização (GOUNET, 2002).

Diante desse quadro, Antunes (2006) refere que parcelas crescentes de desempregados têm tido dificuldades cada vez maiores de reinserção no mercado formal de trabalho, ou seja, a contratação em regime assalariado por tempo indeterminado e com carteira assinada. Essa nova configuração de assalariamento sem regulamentação trabalhista é incorporada ao capital produtivo nas diversas modalidades de trabalho precarizado: trabalhadores terceirizados, subcontratados, part-time, ${ }^{8}$ entre tantas outras formas assemelhadas, que se expandem em escala global.

A aplicabilidade dos princípios do sistema just-in-time ${ }^{9}$ entre unidades industriais é aliada aos princípios de subcontratação, formando uma cadeia produtiva chamada por Harvey $(1992$, p. 145) de "pirâmide de fornecedores": a grande empresa contrata os fornecedores de primeiro nível que, por sua vez, precisarão contratar terceiros etc. Isto significa, em outras palavras, que as empresas de grande porte transferem seus custos com a manutenção de estoques e força de trabalho para as empresas subsidiárias.

Outra consequência advinda da flexibilização empresarial pode ser observada na significativa mudança no perfil da mão de obra ativa, que incidiu diretamente na crescente feminização da força de trabalho, bem como na contratação formal de trabalhadores mais escolarizados. Todas essas inovações trouxeram profundas alterações no mercado de trabalho e na estrutura do emprego, o que pode ser verificado nas ocupações de baixa qualidade, configurados por empregos atípicos, irregulares e em tempo parcial.

O proletariado da indústria verticalizada, típica do sistema taylor-ford é reduzido drasticamente após o ingresso da produção fundamentada nos princípios toyotistas, que propõem o fim dos estoques, a polivalência dos trabalhadores, a criação de células de produção - polo industrial - e círculos de controle de qualidade (CCQ), a terceirização, o trabalho em equipe, a diminuição do "chão da fábrica" e a flexibilidade,

\footnotetext{
${ }^{8}$ A tradução livre do inglês é meio-expediente, e se refere à jornada de trabalho em tempo parcial.

${ }^{9}$ A tradução livre do inglês é no tempo certo e designa o circuito encomenda-produção-entrega eficiente. Esse regime produz apenas encomendas na quantidade necessária tornando desnecessário o estoque e eliminando o tempo de espera entre os postos de trabalho ou venda.
} 
que transfiguram a acumulação do capital físico/financeiro em líquido/especulativo (ANTUNES, 2007).

O processo de desindustrialização oriundo da reestruturação produtiva associa e agrega o trabalho por meio da eliminação de várias funções como supervisão, inspeção, gerências intermediárias etc., transferindo e incorporando ao trabalho produtivo atividades que anteriormente eram realizadas por trabalhadores improdutivos; difundindo-se o operário multifuncional, que é chamado a conhecer desde a limpeza à manutenção das máquinas, para prevenir e/ou resolver problemas e panes (ANTUNES, 2006).

Além dessas medidas, fábricas e indústrias externalizam suas atividades para alcançar uma maior rentabilidade, fazendo crescer o setor de prestação de serviços ou terceirização. Segundo Harvey (1992, p. 143), a partir dessa externalização da produção, houve redução do emprego regular em decorrência do emprego em tempo parcial, temporário ou subcontratado, que gerou dois grupos de trabalhadores: 19) trabalhadores centrais, que ainda preservam emprego em tempo integral que conservam alguns dos direitos trabalhistas e $2^{\circ}$ ) trabalhadores periféricos, empregados geralmente em tempo parcial, com alta taxa de rotatividade, cujas habilidades são encontradas em abundância no mercado de trabalho.

O processo de acumulação produtiva atual, baseado na flexibilização da indústria dispensa um grande número de empregados regulares de sua folha de pagamento. No entanto, por meio de mecanismos diversos de terceirização e subcontratação continua empregando um contingente significativo de trabalhadores de modo indireto sem os vínculos trabalhistas legais, por meio da transferência de partes da produção de determinada mercadoria, anteriormente realizada no interior da fábrica, para o exterior do meio fabril ou para os trabalhadores que vivenciam o desemprego estrutural e que ocasionalmente participam de alguma atividade eventual.

Um exemplo deste processo é dado pela AHA Indústria e Comércio de Roupas Ltda., que, de acordo como o gráfico 1, reduziu drasticamente a contratação formal de trabalhadores na função de costureiros, mas conforme a investigação do Ministério do Trabalho e Emprego (MTE) e Superintendência Regional do Trabalho e Emprego de São Paulo (SRTE/SP) subcontrata 33 oficinas para confeç̧ão das peças da rede, empregando 
trabalhadores sem registros e sem recolhimento do Fundo de Garantia por Tempo de Serviço (FGTS) para a executar a atividade de costura. A AHA é a principal fornecedora da multinacional Zara do grupo espanhol Inditex (PYL; HASHIZUME, 2011).

A pirâmide de fornecedores, para voltar ao termo de Harvey, possui no topo da cadeia a empresa Zara que contrata a intermediária AHA que subcontrata 33 oficinas em que os trabalhadores não possuem qualquer direito trabalhista assegurado. Entretanto, na estatística oficial a empresa AHA reduziu o número de empregados.

Gráfico 1 - Evolução do número de empregados da AHA 2010-2011

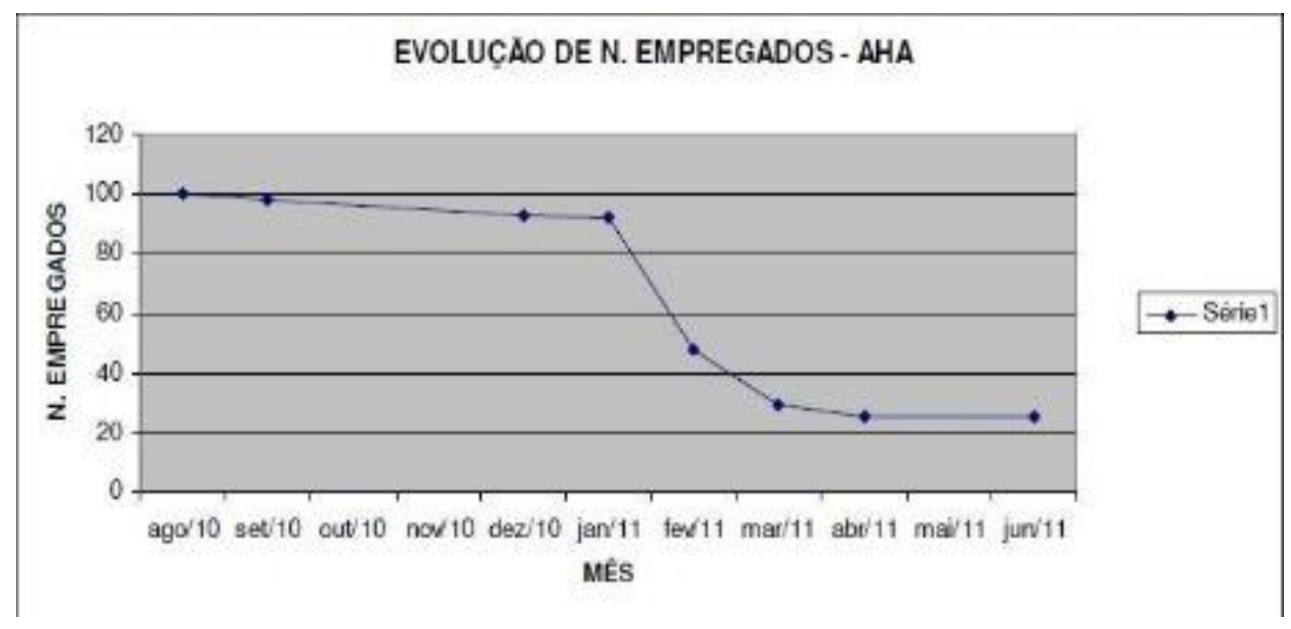

Fonte: Pyl; Hashizume (2011).

Tavares (2004) refere que dentro ou fora da fábrica, o trabalho continua produtivo, emergindo uma nova exploração do trabalho por meio de relações informais em larga escala, tanto no âmbito da produção quanto na circulação de mercadorias. A forma contemporânea do trabalho é dada pela expressão do trabalho social, entretanto, mais complexificado, socialmente combinado e ainda mais intensificado nos seus ritmos e processos, sendo todas estas formas de trabalho precário, partes constitutivas do processo de produção capitalista.

Se o capital conseguisse eliminar completamente o trabalho vivo, não conseguiria a perpetuação de sua reprodução, pois a criação de valores de troca é resultado da 
articulação entre trabalho vivo e trabalho morto, ${ }^{10}$ sendo assim, a categoria trabalho na sociedade contemporânea não perde sua centralidade. Mesmo em atividades mais intelectualizadas/qualificadas não se evidencia o fim do trabalho como medida de valor, mas uma mudança qualitativa, uma inter-relação acentuada das formas de extração de mais-valia relativa e absoluta, que se realiza em escala ampliada e mundializada. Ou nas palavras de Antunes (2006, p. 183): "aumentam os níveis de exploração do trabalho".

\section{Quando a centralidade do trabalho é exigida}

As formas desregulamentadas de gestão da força de trabalho parecem negar a centralidade do trabalho, no entanto, como dito anteriormente, o que de fato acontece é uma redução na proteção social aos trabalhadores, provocando uma reversão das conquistas trabalhistas. Esse conjunto de trabalhadores que se encontram subempregados, desempregados ou aqueles se inserem no mercado por trabalhos eventuais, representam as ocupações trabalhistas não cobertas pelo sistema de proteção social brasileiro.

As estatísticas do Instituto Brasileiro de Geografia e Estatística (IBGE) informam que em um tempo médio de 20 anos ocorreu um amplo processo de desestruturação do trabalho formal no Brasil, acompanhado de altos índices de desemprego, pois em 1982 a taxa de ocupação com carteira assinada em relação à População Economicamente Ativa (PEA) era de 53,38\%, ao passo que em 1992 passou para 47,03\% e no ano de 2002 essa proporção foi equivalente a $42,05 \%$.

Para que se possa avaliar a importância da aposentadoria, ainda de acordo com o

\footnotetext{
10 Para Marx (1996), o desenvolvimento da produção capitalista, caracteriza-se pela combinação do trabalho social que abrevia o tempo necessário para a produção de mercadorias, ao mesmo tempo em que diminui a massa de trabalhadores para um quantum determinado de mercadorias produzidas. Com o emprego do sistema de máquina, a substituição do trabalhador por uma parte do capital constante (aquela parte do produto do trabalho que se torna novamente meio de trabalho) se coloca, produzindo genericamente um excedente de trabalhadores como tendência expressa e apreensível, que atua e se estabelece em larga escala. $O$ trabalho passado surge aqui como meio para substituir o trabalho vivo ou como aquele meio de fazer diminuir o número de trabalhadores. Esta diminuição do trabalho humano, ou trabalho vivo substituído pelo produto do trabalho passado, aparece como especulação capitalista, como meio para aumentar a mais-valia.
} 
senso demográfico do IBGE, a população idosa ${ }^{11}$ do país que era constituída de 2,4\% nos anos 1940, passou nos anos de 1970 e 1980 a representar 3,2 e 4\% respectivamente. No ano de 1996 esta população passou a representar 5,4\% e em 2002 chegou a 8,6\% de toda população brasileira, o que corresponde a 14,5 milhões de pessoas. Esse "envelhecimento" da população brasileira deve-se a redução da taxa de fecundidade ocorrida principalmente a partir dos anos de 1960, além do aumento da expectativa de vida da população, que em 2002 correspondeu a média de 68 anos.

Camarano (2004) aborda que o crescimento da população idosa ocorrido de forma geral em todos os países, trouxe um debate para a Europa acerca da improdutividade do idoso, que passa a ser visto como consumidor ao invés de produtor (também nos gastos públicos), acarretando sobre a população jovem o custo de sustentar a população idosa.

Contrariando a lógica europeia, no Brasil, os dados do Censo do IBGE mostram que no ano de 2000 cerca de $62,4 \%$ de todos os idosos brasileiros eram responsáveis pela renda nos domicílios brasileiros e os cônjuges desses idosos representavam cerca de $22 \%$, revelando que a maioria $(84,4 \%)$ desta população ocupa um papel de destaque no modelo de organização da família brasileira.

Os números do Censo de 2000 revelam também que, em todo país, a proporção de idosos responsáveis pela renda domiciliar, com ou sem cônjuge, que moram com parentes e/ou filhos na mesma casa ${ }^{12}$ e os sustentam é de $64,7 \%$. Camarano e Ghaouri (2003, p. 2) sintetizam:

Duas tendências parecem que podem ser generalizadas: os idosos estão vivendo mais e os jovens estão adiando a idade em que saem da casa dos pais. O período em que os filhos passam como economicamente dependentes de seus pais tem crescido, devido à instabilidade do mercado de trabalho, ao maior tempo despendido na escola e à maior instabilidade das relações afetivas.

Segundo dados da Pesquisa Nacional por Amostra de Domicílio (PNAD) de 1999, a

\footnotetext{
${ }^{11}$ Considera-se idoso a pessoa com idade igual ou superior a 60 anos, conforme o Estatuto do Idoso, sob a Lei no. 10.741, de 01 de outubro de 2003. No entanto, para fins previdenciários, a aposentadoria por idade é concedida aos trabalhadores urbanos do sexo masculino aos 65 anos, e para o sexo feminino aos 60 anos; aos trabalhadores rurais é concedido uma redução de 5 anos, sendo 60 para os homens e 55 para as mulheres. Quanto ao benefício da Assistência Social é concedido, conforme os critérios da Lei Orgânica da Assistência Social (LOAS), aos idosos a partir de 65 anos.

12 Denominado de corresidência.
} 
aposentadoria representava a principal componente de renda para $54 \%$ dos homens idosos e o trabalho a principal componente de renda para $36 \%$ destes homens. Já no caso das mulheres idosas, o rendimento advindo da pensão e aposentadoria representa $80 \%$ do total.

No Brasil, a renda do idoso proveniente da seguridade social pode ser resumida em: a) benefício previdenciário ou aposentadoria (previdência social) e b) benefício de amparo assistencial ao idoso ${ }^{13}$ (assistência social). Esses benefícios não podem ser confundidos, pois seus critérios de acesso se diferenciam na medida em que a aposentadoria é um direito adquirido pelo "mérito" de ter trabalhado e contribuído para a previdência social anteriormente, enquanto que o benefício da Lei Orgânica de Assistência Social (LOAS) não é contributivo, mas para pessoas que vivem abaixo da linha pobreza que no ano de 2000, correspondia àquelas pessoas com renda familiar abaixo de R\$ 75,00 (MARQUES; EUZÉBY, 2005).

O grande problema nesta avaliação acerca da aposentadoria consiste no fato de não existirem mecanismos de proteção ao idoso que sejam equivalentes ao direito de cidadania, portanto, não meritocráticos, isto significa que a seguridade social brasileira não garante ao cidadão, que completa 60 (sessenta) anos ou mais, sua emancipação do mercado de trabalho.

A aposentadoria oriunda da contribuição previdenciária despreza os trabalhadores que se encontram compulsoriamente fora do mercado formal, em função dos atuais rearranjos no mundo do trabalho. Do mesmo modo, o benefício de amparo ao idoso é restritivo, pois destina-se apenas aos idosos que comprovem não possuir meios de prover à própria manutenção ou tê-la provida por sua família (BRASIL, 1990). Todos os outros trabalhadores que não se encontram nessas situações, ao completarem 60 anos de idade, serão obrigados a continuar a mercê do mercado, pagar aposentadoria privada ou aumentar a fila de espera para o benefício da LOAS.

De acordo com Telles (1999, p. 93), adotou-se no Brasil "uma espécie de contrato de serviços em que o contribuinte estabelece com o Estado", ou ainda, um "peculiar" modelo de cidadania que nega os direitos políticos e regras de equivalência jurídica ao vincular os direitos sociais ao pertencimento corporativo como garantia de existência

\footnotetext{
${ }^{13}$ Lei no. 8742/1993 da Lei Orgânica de Assistência Social (LOAS).
} 
cívica, como é o caso da previdência social que ocorre mediante contribuição anterior. A aposentadoria, parte integrante da previdência social, é fundamentada na sociedade salarial e reconhece a cidadania com base no exercício do trabalho regulamentado.

A aposentadoria pública restringe-se aos trabalhadores que de alguma forma contribuíram anteriormente (direito restrito). Mas atualmente os "novos" postos de trabalho ofertadas contrariam mesmo o direito restritivo da aposentadoria contributiva devido à grande informalidade. Isto nos leva a afirmar que quando se trata da seguridade social, o trabalho regulamentado continua a ocupar uma função central.

A centralidade do trabalho na previdência social é reforçada também pelos argumentos de "déficits previdenciários" que defendem o equilíbrio orçamentário da seguridade social por meio da "redução de aposentadorias pagas pelo sistema público, o alargamento do período de contribuição necessária para o recebimento de aposentadorias e, finalmente, a expansão dos fundos de pensão"14 (BONALDI, 2007, p. 58).

Os fundos de pensão dependem da capacidade contributiva de cada trabalhador porque são oriundos de arrecadações privadas, reforçando mais uma vez a vinculação ao emprego exigida para a seguridade social. Assim, a privatização da seguridade trabalhista regida completamente pela lei de mercado reforça o abandono de um projeto universal de seguridade social com distribuição de renda.

A grande expansão dos parques industriais nos anos de 1970 generalizou o trabalho assalariado em nível nacional e ampliou os benefícios previdenciários. Assim, pode-se referir que os aposentados de hoje são os herdeiros de certa expansão econômica, de tentativas de empregos estáveis e formais, da proteção social como forma de atendimento às necessidades da classe trabalhadora etc., mesmo que se reconheça que o processo de modernização no Brasil foi extremamente segmentado, possuindo setores industriais modernos convivendo com setores tradicionais da economia agrário-exportadora (MOTA, 2000).

Esse perfil da proteção social divide os trabalhadores por suas diferenciações de

\footnotetext{
${ }^{14}$ Para Bonaldi (2007, p. 56), os fundos de pensão resultam de associações de trabalhadores ou sindicatos com ou sem a participação de empresas ou patrões, originando uma previdência complementar associativa, ou seja, "instituições financeiras administradas por gestores [...] que reúnem gigantescas massas de capital, as poupanças de família e de pessoas físicas [...] para aplicá-las onde quer que elas se mostrem rentáveis".
} 
consumo: a) em cidadãos que podem usufruir de serviços que contribuem na melhoria das condições de vida de sua família; e b) em não cidadãos que ficam a mercê da privatização dos serviços sociais ou lutam por serviços assistenciais não contributivos (MOTA, 2000). Embora os direitos sociais sejam universais por orientação da constituição brasileira de 1988, as prioridades orçamentárias não atendem aos interesses coletivos da sociedade.

No caso da previdência social, e especificamente da aposentadoria, fundamentada pelo trabalho formal, surgem duas consequências diretamente relacionadas à retração do emprego regulamentado e já esboçadas anteriormente: 1a) A contribuição anterior, assegurada pelos idosos que possuíam cidadania regulada, permite aos aposentados de hoje a sustentação de suas famílias e, como citado acima, o número de jovens que corresidem com trabalhadores aposentados vêm aumentando. Constata-se então, que no Brasil a dependência financeira não acontece por parte dos aposentados, mas por parte dos filhos adultos que não estão conseguindo uma inserção no mercado de trabalho que garanta renda. 2a) 0 trabalho, mesmo central no processo de produção e reprodução humana, em virtude do alargamento dos postos de trabalho informais não consegue mais dar sustentabilidade financeira ao sistema previdenciário desde a década de 1990. A aposentadoria, que é inerente a esse sistema e constitui-se como uma renda de substituição, e, portanto, associada a um trabalho contributivo anterior, está fadada a uma redução dramática nas próximas décadas, com ameaça de falência deste padrão de seguridade social, possibilitando como única via de acesso a seguridade privada.

A capitalização da seguridade não é uma opção que beneficia os trabalhadores, pois seu financiamento, além de negar qualquer concepção de direito social universal, é ainda, segundo Mota (2000, p. 179), uma estratégia de "remercantilização da força de trabalho e um redirecionamento imprimido pelo capital às conquistas do trabalhador, no tocante à reprodução ampliada de sua força de trabalho".

O financiamento da aposentadoria é alicerçado no trabalho regulamentado, portanto, sujeito também ao mercado, revelando seu caráter contraditório, reproduzindo diferentes níveis de consumo entre os trabalhadores formais e os trabalhadores que não contam com o contrato formal da carteira de trabalho. 
Alguns argumentos liberais são utilizados por teóricos da previdência, como no texto de Camarano, Pasinato e Lemos (2007, p. 26), que referem que o desemprego afeta a previdência pública, pois "de um lado, cresce a demanda por benefícios previdenciários e, por outro, diminui a oferta de contribuintes". Pochmann (2003), no entanto, chama a atenção para esse tipo de análise que incorre numa inversão de papéis, uma vez que não são os gastos sociais que determinam o agravamento da crise da seguridade social brasileira, mas o contrário.

Entende-se que embora a longevidade atual da população brasileira possa requerer uma revisão de idade mínima para a aposentadoria, como o que já vem ocorrendo nos países europeus, não se deve inverter a lógica da idade ativa. São os adultos em idade ativa que devem ocupar os postos de trabalho, e não o idoso ser obrigado a trabalhar indefinidamente para garantir as necessidades mais básicas de sua família. Permanecer no mercado de trabalho deve ser de fato uma opção pessoal do idoso, e não uma imposição social.

Em resumo, a proteção social da população inativa não pode ser subsumida pelo mercado. Pois são as relações de maximização de lucro deste mercado que criam as diversas formas de ocupação informal e o elevado nível de desemprego na sociedade.

\section{Considerações finais}

A redução dos postos de trabalhos regulamentados parece negar a centralidade do trabalho para o modo de produção burguês. No entanto, quando se trata da seguridade social, somente os indivíduos que contribuem com a previdência - uma minoria - podem usufruir dos direitos da cidadania regulada, como a aposentadoria. De maneira simultânea à expansão do conjunto de expressões da "questão social" e retração da proteção social brasileira com ameaça aos seus principais benefícios públicos, existe um discurso da "crise de sustentabilidade financeira da previdência social", da "necessidade de ajuste, alteração e reforma desse sistema"; das "elevadas contribuições e custo com a força de trabalho que conduzem ao elevado desemprego" etc., que sugere uma dinamização do processo e ampliação do mercado como principal aparelho regulador ao acesso dos trabalhadores à previdência social.

O trabalhador idoso continua vinculado ao mercado de trabalho, mesmo depois 
de diversas décadas inserido no processo laboral, porque se vê obrigado a garantir o seu sustento e dos membros de sua família, os quais em função do processo de reestruturação produtiva, não conseguem um trabalho capaz de fornecer os meios para a satisfação de necessidades básicas. Neste contexto, o assalariamento do trabalhador idoso se torna a principal referência desta família.

O sistema de proteção social e seus princípios de universalização de direitos sociais têm sido substituídos por um sistema de focalização compensatória, com impactos sobre a "questão social", desprezando a cidadania social e reduzindo drasticamente o acesso aos bens públicos e a garantia de direitos básicos. A aposentadoria é um destes direitos negados com o deslocamento de serviços essenciais para o âmbito privado, por meio de ajustes que, de um lado sugerem a privatização desse direito por meio do seguro privado; e de outro alteram a estrutura institucional de atuação do Estado, restringindo-lhe a segmentos populacionais.

\section{Referências}

ADORNO, T. W.; HOKHEIMER, M. A dialética do esclarecimento: fragmentos filosóficos. Rio de Janeiro: Jorge Zahar, 2006. (Excursos I e II).

ALVES, G. Toyotismo como ideologia orgânica da produção capitalista. Org \& Demo, Marília, v. 1, n. 1, p. 3-15, 2001.

ANTUNES, R. Adeus ao trabalho? ensaio sobre as metamorfoses e a centralidade do mundo do trabalho. 12. ed. São Paulo: Cortez, 2007.

. Os sentidos do trabalho: ensaio sobre a afirmação e a negação do trabalho. 8. ed. São Paulo: Boitempo, 2006.

BONALDI, E. V. Incerteza prolongada. Sociologia Ciência \& Vida, São Paulo, ano 1, n. 3, p. 56-63, 2007.

BRAGA, R. Mercadoria descartável. Sociologia Ciência \& Vida, São Paulo, ano 1, n. 3, p. 40-47, 2007.

BRASIL. Constituição (1988). Constituição da República Federativa do Brasil. 4. ed. São Paulo: Saraiva, 1990. (Série Legislação Brasileira).

CAMARANO, A. A. (Org.). Os novos idosos brasileiros: muito além dos 60 ? Rio de Janeiro: Ipea, 2004.

CAMARANO, A. A.; GHAOURI, S. K. E. Famílias com idosos: ninhos vazios? Rio de 
Janeiro: Ipea, 2003. (Texto para discussão, n. 950).

CAMARANO, A. A.; PASINATO, M. T. M.; LEMOS, V. R. Cuidados de longa duração para a população idosa: uma questão de gênero? In: NERI, A. L. (Org.). Qualidade de vida na velhice: enfoque multidisciplinar. Campinas: Alinea, 2007.

FREITAG, B. A teoria crítica: ontem e hoje. 5. ed. São Paulo: Brasiliense, 2004.

GOUNET, T. Fordismo e toyotismo na civilização do automóvel. São Paulo: Boitempo, 2002.

HARVEY, D. Condição pós-moderna: uma pesquisa sobre a modernidade, São Paulo: Loyola, 1992.

LAZZARATO, M.; NEGRI, T. Trabalho imaterial: formas de vida e produção de subjetividade. Rio de Janeiro: DP\&A, 2001.

LESSA, S. A materialidade do trabalho e o trabalho imaterial. Revista Outubro, São Paulo, n. 8, p. 27-46, 2003.

MARQUES, R. M.; EUZÉBY, A. Um regime único de aposentadoria no Brasil: pontos para reflexão. Nova economia, Belo Horizonte, v. 15, n. 3, p. 11-29, 2005.

MARX, K. O capital: crítica da economia política. São Paulo: Nova Cultural, 1996. (Coleção Os economistas, v. 2).

MOTA, A. E. Cultura da crise e seguridade social: um estudo sobre as tendências da previdência e da assistência social brasileira nos anos 80 e 90. 2. ed. São Paulo: Cortez, 2000.

POCHMANN, M. Gastos sociais, distribuição de renda e cidadania: uma questão política. Econômica, Niterói, v. 5, n. 1, p. 111-114, 2003.

PYL, B.; HASHIZUME, M. Roupas da Zara são fabricadas com mão de obra escrava. Repórter Brasil, ago. 2011. Disponível em:

<http://www.reporterbrasil.org.br/exibe.php?id=1925>. Acesso em: 10 set. 2011.

ROSENFIELD, C. L. Autonomia outorgada e apropriação do trabalho. Sociologias, Port Alegre, ano 6, n. 12, p. 202-227, jul./dez. 2004.

SEARLE, J. R. Minds, brains, and programs. Behavioral and Brain Sciences, Cambridge, v. 3, n. 3, p. 417-457, 1980.

TAVARES, M. A. Os fios (in)visíveis da produção capitalista: informalidade e precarização do trabalho. São Paulo: Cortez, 2004.

TELLES, V. S. Direitos sociais: afinal do que se trata? Belo Horizonte: Ed. UFMG, 1999. 